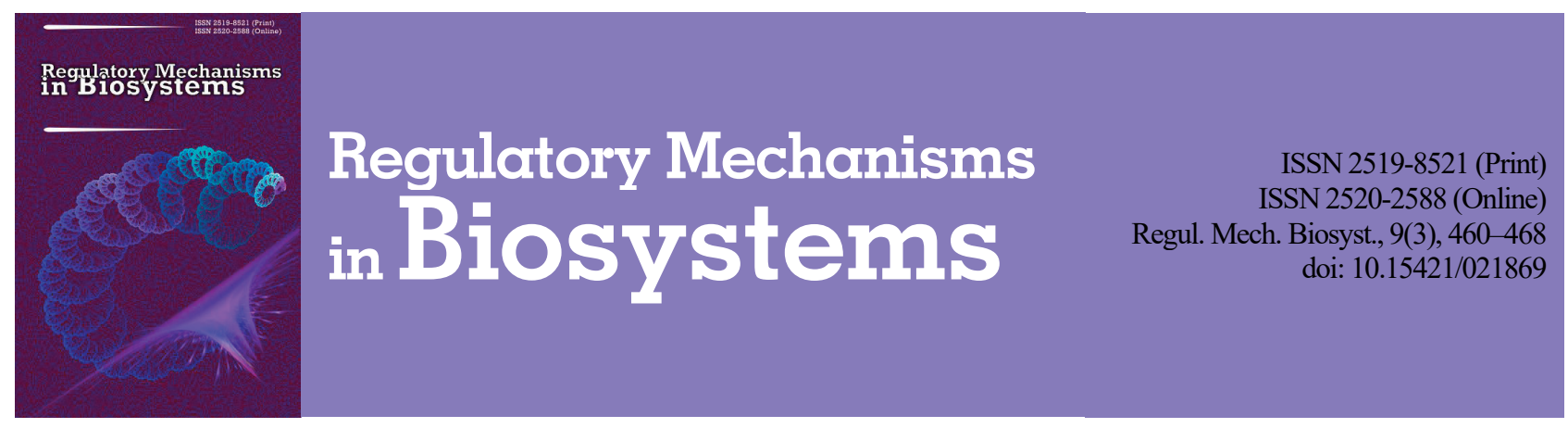

\title{
Pathomorphology of peripheral organs of immunogenesis in cats with spontaneous feline infectious peritonitis
}

\author{
M. R. Khalaniia, G. I. Kotsyumbas, V. V. Pritsak \\ Stepan Gzhytskyi National University of Veterinary Medicine and Biotechnologies, Lviv, Ukraine
}

Article info

Received 29.06.2018

Received in revised form 07.08 .2018

Accepted 09.08.2018

Lviv National University of Veterinary Medicine and Biotechnologies named after S. Z. Gzhytskyj,

Pekarska st., 50

Lviv, 79010, Ukraine

Tel.: + 38-032-260-28-89.

E-mail:

martadocvet@gmail.com
Khalanïa, M. R., Kotsyumbas, G. I., \& Pritsak, V. V. (2018). Pathomorphology of peripheral organs of immunogenesis in cats with spontaneous feline infectious peritonitis. Regulatory Mechanisms in Biosystems, 9(3), 460-468. doi:10.15421/021869

This article presents the results of pathomorphological research on the spleen and mesenteric lymph nodes of 23 dead cats aged from 3 months to 7 years, which in their lifetimes (according to anamnesis, clinical signs, laboratory-instrumental methods of examination and VetExpert FCoV Ab express test) had been diagnosed with infectious peritonitis. All the animals were domestic. Blood was drawn from the subcutaneous vein of the forelimb of the diseased cats. We determined ESR, morphological parameters of blood and content of hemoglobin. For histological and histochemical examinations, we selected samples of spleen and mesenteric lymph nodes, which were fixated in 10\% aqueous solution of neutral formalin, Carnoy's and Bouin's solutions. The prepared histological sections were stained using haematoxylin and eosin, Van Gieson's stain, methyl green-pironin stain (Brashe), PASreaction (McManus), alcian blue and Congo red. Hematological parameters during 3 weeks of clinical progression of the disease among the cats demonstrated a decrease in the hemoglobin content and in the number of erythrocytes and leukocytes. Possible decrease in the number of lymphocytes indicated the development of an immune-deficiency state. Also, during the development of disease, the animals had possible increase in ESR, which indicated the development of an inflammatory process in the organism and decrease in the number of thrombocytes, which conditioned development of disseminated intravascular coagulation. The anatomical pathology autopsy showed that in most animals the spleen was diminished in size, the surface of the organ was tuberous, the capsule was wrinkled and mat, the edges were sharpened. The histostructural change was accompanied by a sharp depletion of the lymph nodes and reduction in the number of micro- and macrophages, which indicated the reduction of white pulp, rapid inhibition of the activity of T- and B-lymphocytes, plasmacytic and macrophage reaction and manifested in development of immune-deficient condition of the organism. In this process, the reticular carcass of the lymph nodes saturated with PAS-positive and eosinophilic masses was clearly manifested, which indicated formation of fibrinoid. In the spleen of 5 individuals, during staining using Congo red, we found deposition of amyloid masses both in the intima of the blood vessels and along the reticulary fibers of the lymph nodes. In the cytoplasm of macrophages, we found pyroninophilic formations. In two cases, we observed blood accumulation of red pulp and bleeding following the reduction of white pulp, and in one case fibrinogenous perisplenitis. In the mesenteric lymph nodes of most of the cats which had suffered from infectious peritonitis, we determined that edema, exposure of the reticular soft skeleton (stroma) of adrenal and paracortical zones, dilation of the border and central sinuses and thrombosis of vessels were followed by steep decrease in the number of T- and B-lymphocytes, plasma cells, micro- and macrophages, which indicated the development of atrophic processes of lympoid tissue and immune-suppression. In three cases, in mesenteric lymph nodes of cats, we determined development of sinus histiocytosis. The changes determined in the spleen and lymph nodes of the cats which had suffered from FIP indicate immune-suppressed condition and steep decrease in the functional ability of the organs and organism in general.

Keywords: spleen; lymph nodes; lymphocytes; macrophages; reticular carcass.

\section{Introduction}

Feline infectious peritonitis (FIP) is an immune-conditioned disease of domestic and wild cats, which is caused by the virulent cat coronavirus, which is one of the main infectious causes of death of young cats, and which threatens the survival of wild cats (Baydar et al., 2014; Kim et al., 2016; Ziółkowska et al., 2017). Occurrence of cases of cats suffering FIP is several times higher among the adult and young cats, which are kept in research centers or animal shelters. $80 \%$ of FIP cases are observed among young cats up to two years old, and $50 \%$ among kittens up to 7 months. Outbreaks of FIP can also occur in places where cats concentrate, where previously not a single case had been recorded (Knotek et al., 2000; Pedersen et al., 2009, 2014, 2016).

Despite the fact that pathogenesis is complicated and not fully clear, the pathogen is FIP (FIPV) virus, monocytic / macrophago-tropic mutated feline enteric coronavirus (FECV), which is widely distributed among cats all over the world (Crawford et al., 2017, Pedersen, 2014a, b). Macrophages with the virus cause a significant inflammatory reaction, leading to multisystemic pyogranulomatous vasculitis. Over time, the histiocytic population is replaced by a lymphoplasmatic population (Crawford et al., 2017)

Feline coronovirus (FCoV) belong to the genus Alphacoronavirus and usually causes mild symptoms of disorders of the gastrointestinal tract in cats. A low percentage of seropositive animals (5\% to $12 \%$ ) can develop feline infectious peritonitis (FIP). There are two known serotypes, among which type I is the commonest (80-95\%), whereas the less common type II of FCoV may have formed due to a double process of recombination between type I of FCoV and type II of canine coronavirus (CCoV) (Le Poder et al., 2013; Bálint et al., 2014).

The critical factor in FIP pathogenesis is the function of cell-conditioned immunity, which can either prevent or allow full development of clinical disease among the infected animals. In the first case, the patient 
can develop a latent infection, making him a carrier of a virus (Knotek et al., 2000). Cats with high humoral immunity and low or absent cellular-conditioned immune response against FIPV, obtain stable viremia and exudative form of FIP. The exudative form of the disease occurs as a result of broad sedimentation of immune complexes in the walls of blood vessels and activation of the complement which causes damage to the vessels, development of vasculitis and secretion of serum and protein in the body cavities. Cats with partial cellular-conditioned immune responses combined with humoral immune reactions develop a more chronic non-exudative form of FIP, which is characterized by immune-conditioned (hypersensitivity of delayed type) granulomatosis, often with perivascular damage to organs of the abdominal cavity, lungs, brain and eyes (Baydar et al., 2014).

FIPV can infect monocytes and macrophages, causing systemic infections and fatal diseases, whereas FECV only replicates in mature intestinal epithelium, which mainly causes non-symptomatic infection (Hora et al., 2016). Currently, it is known that the main links of the FIP pathogenesis are a systemic infection with FIPV, effective and stable replication of the virus in monocytes and activation of infected monocytes. This activation of monocytes and macrophages leads directly to pathological peculiarities of FIP, including vasculitis, secretions into the body cavities, with development of fibrinogenous and granulomatous inflammatory damage (Kipar et al., 2014). It is considered that the overwhelming of the immunity is conditioned by disorders in the co-working of T-lymphocytes and macrophages infected with FIP. Certainly, stress or immune suppression play an important part in manifestation of FIPV (Knotek et al., 2000).

The level of organism protection depends on the efficiency of the immune system which is the most important component of animal health, therefore the study of the defects of organs of immune system, which occur in the case of infectious diseases is one of the main orienttations in researching the development of pathological state of animals. Due to the important role of the immune system in development of FIP, the objective of our study was to determine the pathomorphological changes in the peripheral organs of the immune system of cats suffering from infectious peritonitis. Spleen and lymph nodes constantly interact with antigens in the blood of animals, therefore structural changes which follow the development of FIP can help in determining some aspects of the mechanism of development of immune-pathological processes in cats.

\section{Materials and methods}

For determination of hematological parameters, blood was drawn twice out of the subcutaneous vein of the forelimb of 5 diseased animals. Prior to this, the fur was cut and the skin was disinfected. As an anticoagulant, we used EDTA K2. The number of erythrocytes and leukocytes in the blood was determined using the standard method with a hemocytometer. Content of hemoglobin was determined colormetrically using the hemoglobin-cyanide unified method, ESR - using Panchenkov's method (Kondrahin, 2014; Uillard et al., 2014). The data was statistically analyzed using the StatPlus program, reliability of the obtained data was determined using ANOVA.

The pathomorphological studies were conducted at the Department of Normal and Pathological Morphology and Veterinary Forensics of Lviv Stepan Gzhytskyi National University of Veterinary Medicine and Biotechnologies and the Deartment of Pathologies of the University of Wrocław (Republic of Poland) during 2016-2018. We conducted a pathoanatomical study of the bodies of 23 cats aged from 3 months to 7 years, who while still alive had been diagnosed with FIP (based on anamnesis, clinical signs, laboratory-instrumental methods of study and express-diagnostics (VetExpert FCoV Ab express test).

For histological study, we cut fragments of the spleen and mesenteric lymph nodes of $1 \times 1 \mathrm{~cm}$ size, then put them in $10 \%$ aqueous solution of neutral formalin for fixation, with a layer of cheesecloth for full submergence. The fixated patho-material was washed in tap water during $24 \mathrm{~h}$, and using a sharp blade, thin $2 \mathrm{~mm}$ thick panels were accurately cut. Further, the cut fragments of the selected tissues were dehydrated in spirits in the order of increasing content of alcohol $\left(70^{\circ}, 80^{\circ}, 90^{\circ}, 96^{\circ}-\mathrm{I}\right.$ and $96^{\circ}-$ II) for 24 hours in each spirit. After dehydrating the samples, they were put for an hour into a mixture of $96^{\circ}$ spirit and chloroform in $1: 1$ proportion, and then into pure chloroform-I for an hour and chloroform-II for an hour. Then, the patho-material was put into a melted mixture of chloroform and paraffin in $1: 1$ proportion for an hour in a thermostat at $+37{ }^{\circ} \mathrm{C}$. Next, the tissue fragments were put in two portions of melted paraffin for 2 hours in each, in a thermostat at $+56^{\circ} \mathrm{C}$. The patho-material fragments from the paraffin-II were transferred into forms, which were further filled with melted paraffin and cooled in cold water. The obtained paraffin blocks were glued to wooden blocks. For histological study, the samples of the studied tissues were fixated in Carnoy's and Bouin's solutions. Out of paraffin blocks, $7 \mu \mathrm{m}$ thick histological sections were made on MS-2 sliding microtome. The obtained histological sections were removed from the knife with a soft brush and transferred into warm distilled water (40 degrees $\mathrm{C}$ ), submerging it starting from the surface which contacted the knife. After becoming spread in the warm water, the histological sections were taken out with a microscope slides. The microscope glasses with histological sections were put into thermostat for $24 \mathrm{~h}$ at a temperature of $+37^{\circ} \mathrm{C}$. The histological sections stained with haematoxylin and eosin were deparaffinated in two portions of xylene for $2 \mathrm{~min}$ in each portion, transferred to spirits at decreasing concentration for $2 \mathrm{~min}$ in each concentration $\left(96^{\circ}, 80^{\circ}, 70^{\circ}\right)$ and put into distilled water for $3 \mathrm{~min}$, and then transferred to Ehrlich's hematoxylin for $5 \mathrm{~min}$, rinsed in distilled water over $3 \mathrm{~s}$. Then the sections were transferred to tap water for $5 \mathrm{~min}$. The differentiation was made in $1 \%$ solution of hydrochloric acid $(3 \mathrm{~s})$, rinsed in tap ( $5 \mathrm{~min})$ and distilled ( $3 \mathrm{~s}$ ) water. The histological sections were put in $0.1 \%$ aqueous solution of eosin for $0.5 \mathrm{~min}$ and washed with distilled water. The histological sections were dehydrated in spirits in order of increasing concentration $\left(70^{\circ}, 80^{\circ}, 96^{\circ}\right)$ - by $2 \mathrm{~min}$, cleared in two portions of xylene for $2 \mathrm{~min}$ and put into Canada balsam. Also, the histological sections were stained with Van Gieson's solution, methyl green-pironin stain (Brashe), PAS-reaction (McManus method), alcian blue (Steedman's method) and Congo red for detection of amyloids (Pyrs, 1962; Merkulov, 1969; Goral's'kyj et al., 2005). The prepared histological preparations were analysed using a Leica DM-2500 (Switzerland) light microscope, photographed using a Leica DFC450C camera with Leica Application Suite Version 4.4 software.

\section{Results}

In veterinary clinics of Lviv, during the examination of diseased cats with signs of flaccidity, reduction of appetite, loss of weight and ascites, 5 animals were diagnosed with FIP. The palpatory mesenteric lymph nodes were enlarged, one cat was diagnosed with uveitis. The animals were monitored during a month. After the cats' owners had contacted the clinic for the first time, blood was drawn out of the subcutaneous vein of the cats' forelimbs. Over three weeks of clinical progression of the disease, the hematological parameters of the diseased cats significantly changed towards possible decrease in lymphocytes. During the first examination of the animals' blood parameters, we determined regenerative shift of neutrophils to the left and gradual increase in ESR. After a second examination 3 weeks later, we found nuclear shift of neutrophils to the right $(\mathrm{P}<0.01)$ and possible decrease in the number of lymphocytes $(\mathrm{P}<0.01)$ following a normal level of leukocytes. At the same time, the ESR increased by more than three times $(\mathrm{P}<0.01)$, and the number of thrombocytes $(\mathrm{P}<0.05)$ and the content of hemoglobin steeply decreased (Table 1).

The analysis of the obtained results allows us to state that over 3 week clinical progression of the disease, the monitored cats underwent a steep decrease in the hemoglobin concentration, number of erythrocytes and leukocytes. Possible decrease in the number of lymphocytes $(\mathrm{P}<$ 0.01 ) indicated the development of an immune-deficiency condition. Also, in the process of the disease's development, the animals possibly had an increase in ESR $(\mathrm{P}<0.01)$, which indicates the development of inflammatory process in the organism, and decrease in the number of thrombocytes $(\mathrm{P}<0.05)$ led to the development of disseminated intravascular blood coagulation (DIC syndrome). The general condition of the examined cats steeply declined Three of the cats were euthanized at the owners' request, the other two died. 
Table 1

Hematological parameters of blood of cats during the clinical progression of FIP $(n=5 ; x \pm S D)$

\begin{tabular}{lccc}
\hline \multicolumn{1}{c}{ Parameter } & Norm & $\begin{array}{c}\text { First } \\
\text { examination }\end{array}$ & $\begin{array}{c}\text { Replication } \\
\text { after 3 weeks }\end{array}$ \\
\hline Leukocytes, g/l & $10.5-15.5$ & $25.5 \pm 1.9$ & $5.9 \pm 0.4^{* * *}$ \\
Erythrocytes, corpuscles per liter & $6.6-9.4$ & $7.6 \pm 0.4$ & $5.6 \pm 0.3^{* * *}$ \\
Hemoglobin, g/1 & $90-155$ & $114.6 \pm 6.5$ & $76.8 \pm 5.3$ \\
Thrombocytes, g/l & $200-600$ & $465.0 \pm 11.4$ & $79.8 \pm 2.8^{*}$ \\
\hline \multicolumn{1}{c}{ Leukogram } & & & \\
\hline Band neutrophils, \% & $3-9$ & $14.4 \pm 1.6$ & $5.6 \pm 1.2$ \\
Neutrophils with segmented nuclei, \% & $40-45$ & $56.0 \pm 2.4$ & $84.4 \pm 1.8^{* *}$ \\
Eosinophils, \% & $2-8$ & $3.4 \pm 2.7$ & 0 \\
Basophils, \% & $0-1$ & 0 & 0 \\
Monocytes, \% & $1-5$ & $4.2 \pm 1.2$ & $5.4 \pm 1.0$ \\
Lympocytes, \% & $36-51$ & $22.0 \pm 2.4$ & $4.6 \pm 0.9^{* *}$ \\
ESR, mm $/ \mathrm{h}$ & $2-6$ & $22.6 \pm 1.2$ & $67.4 \pm 3.4^{* *}$ \\
\hline
\end{tabular}

Note: ${ }^{*}-\mathrm{P}<0.05,{ }^{* *}-\mathrm{P}<0.01, * * *-\mathrm{P}<0.001$ compared to the first study.

During the anatomical pathology autopsy of the bodies of 23 cats which died of infectious peritonitis over 2016-2018, the changes in spleen were not of the same type. In most cases, we observed a decrease in size of the spleen. The surface of the organ was tuberous, the capsule was wrinkled and mat, the edges were sharpened (Fig. 1).

During the histological examination of the histological preparations of such spleens, we determined disorganization of the connective-tissue stroma, atrophy of white pulp. The connective tissue capsule of the spleen was uneven, folded. Disruption of the fibers and edema of trabeculae and walls of vessels were followed by their saturation with PAS-positive protein masses. In this process, decreases in the volume of lymph nodes were clearest,which had no clearly distinguished zones and also were observed to have thinning or even reduction in lymph cords (Fig. 2).

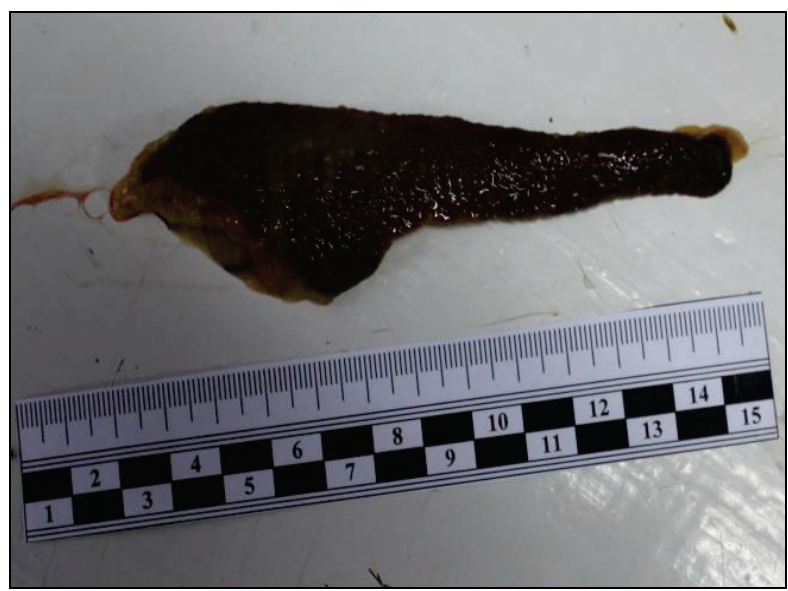

Fig. 1. Shrunken spleen of a cat witht FIP: the surface is tuberous, the capsule was wrinkled, overlapped in some places

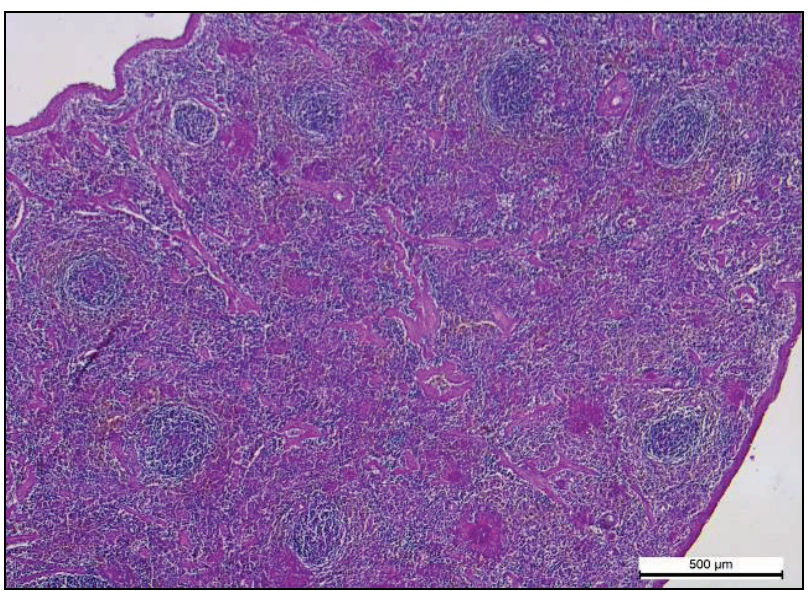

Fig. 2. Spleen of a cat with FIP: the capsule is folded; the saturation of trabeculae and walls of vessels with PAS-positive masses; PAS-reaction
It should be mentioned that the structure of the vessel walls of the organ was damaged. On the preparations stained with haematoxilin and eosin, the walls of central arteries of the lymph nodes either spread, the basal membrane was damaged, endothelial cells were turbid, the cytoplasm transilluminated, nuclei pyknotic or lysed, in some places desquamated. Damage to the endothelial cells led to increased penetrability and disorders in blood flow (Fig. 3). Alongside the changes in endothelial cells, plasmatic saturation of the walls and their fibrinoid swelling occurred. The enlarged vessel walls of the arterioles manifested clear alcianophilia and fuchsinophilia on the preparations stained using Steedman's and McMannus' methods. As they enlarged, their translumminance decreased, which reflected negatively in the rheological properties of the blood. Accumulations of glycosaminoglycans and glycoproteins indicated disorders of collagene and elastic fibers of the vessel walls and development of mesenchymal proteinosis. On the preparations stained with iodine acid-Schiff, the enlarged walls of arteries and arterioles demonstrated a bright PAS-positive reaction, which indicated the development of fibrinoid swelling of vessels (Fig. 4).

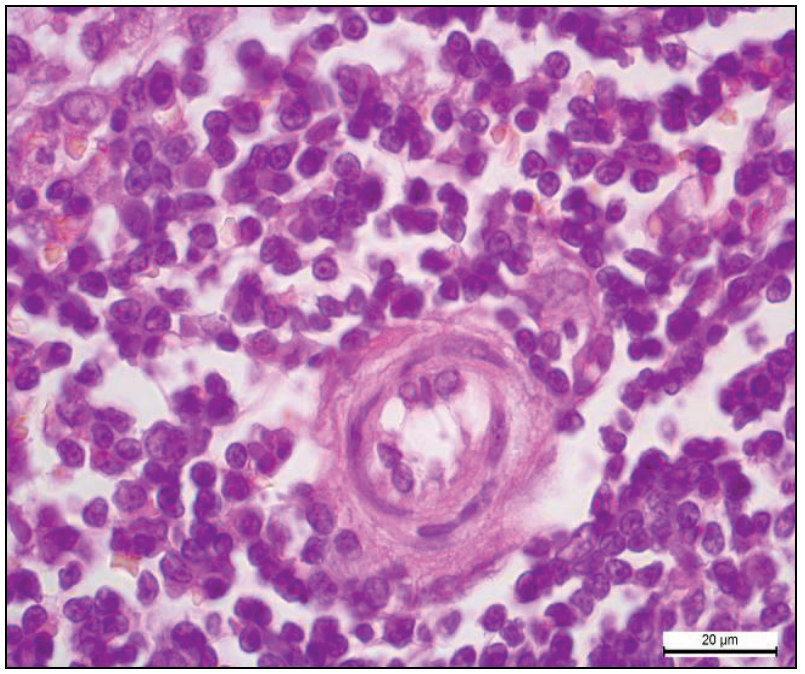

Fig. 3. Spleen of a cat with FIP: central artery of lymph node; endothelium cells of arterioles are turbid, desquamated at some places; hematoxilin and eosin

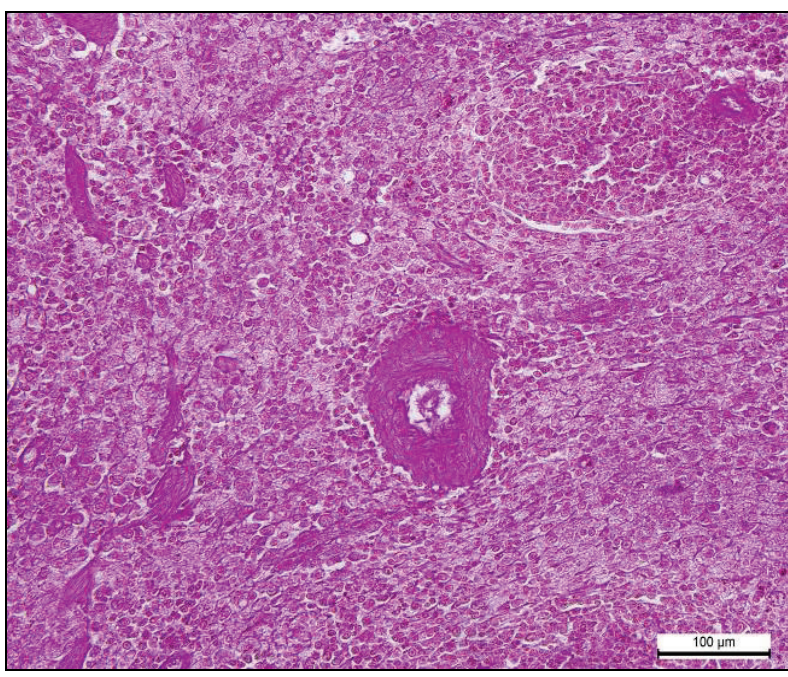

Fig. 4. Spleen of a cat with FIP: the depositions of PAS-positive protein mass in walls of arteries; PAS-reaction

Mostly small in volume, the lymph nodes were a sharply narrowed periarterial T-zone, where the cells were distributed. We observed disorders in the structure of white pulp and quantitative decrease of small, average lymphocytes and macrophages. A steep decrease in the lymphoid population of cells in the lymph nodes and decrease in the content of micro- and macrophages in red pulp was clearly observed in the preparations stained with methyl green-pyronin. A small accumulation of 
T-lymphocytes stained in blue-green was freely positioned around the central artery of the lymph node. Lymphopoiesis and plasmacytic reactions were inhibited (Fig. 5). Often, turbid lymphocytes with decomposing nuclei were found among the cells of the periarterial zone. Along with decrease in the number of lymphocytes, we observed hyperplasia and hypertrophy of reticular cellular elements and their transformation into macrophages. Due to the fact that this zone is enriched with interdigitating cells - macrophages able to fixate complexes of antibodies and antigens on their surface, hypertrophied macrophages were found among the small population of spread lymphocytes. Cytoplasm of swollen, hypertrophied macrophages stably contained pirinophilic elements, and nuclei were in the state of pyknosis or lysis. Also, in the macrophages' cytoplasm, we found vacuoles of different size (Fig. 6). It is known that these particular macrophages are targeted cells, where the coronavirus replication takes place. During absence of adequate cellular immune reaction which occurs in FIP, and even with the presence of specific antibodies, the virus probably continues reproducing in the macrophages (Rjemsi \& Tennant, 2005; Kudrjashov \& Balabanova, 2011). We microscopically found pironinophilic elements in cytoplasm of macrophages of lymph nodes, which indicates that coronavirus replication takes place in macrophages.

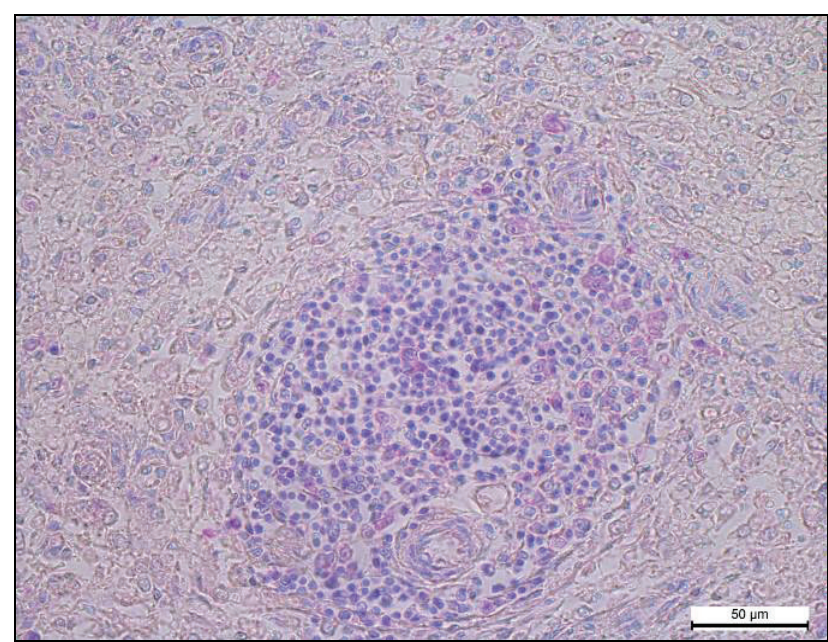

Fig. 5. Spleen of a cat with FIP: steep decrease in the number of lymphocytes in lymph nodes; methyl green pironin

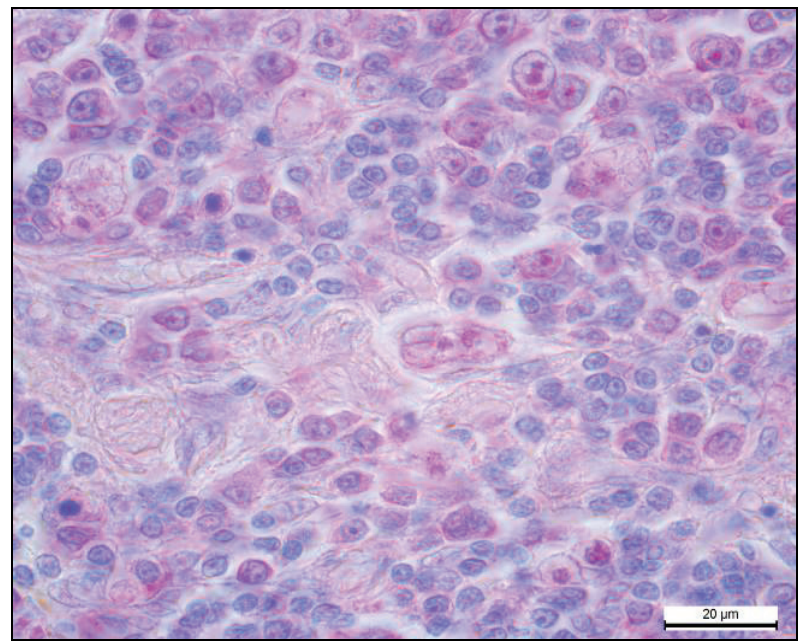

Fig. 6. Spleen of a cat with FIP: macrophages with pironin elements among lymphocytes in lymph node; methyl green-pironin

In the marginal (border) zone of a lymph node, which is the place where white pulp is replaced by red pulp, we found no subpopulations of lymphocytes, and the mantle zone contained single cellular elements. The reticular carcass of both marginal and mantle zone became exposed, and the number of micro- and macrophage cells in the red pulp sharply decreased.
During the monitoring of white pulp reduction, we determined that walls of sinusoids of small vessels in the border (marginal) zone and mantle zone demonstrated clear fuchsinophility on preparations stained with iodine acid-Schiff. The reticular carcass, walls of vessels and sinuses of lymph nodes of the spleen were saturated with PAS-positive protein masses, which in one case manifested highly intense fuchsinophility in the marginal and mantle zones, in other cases - in lymph nodes (Fig. 7). It is possible that damage in the structure of the walls of vessels of microcircular flow caused increase in penetrability in blood vessels, sinusoids, insudation of highly molecular proteins and glycoproteins of blood, leading to disorders in protein-carbohydrate composition of the main substance. At the same time, we observed partial decomposition of fiber structures of collagen fibers. In atrophied lymph nodes, we found accumulations of homogenous mass in the form of fuchsinophilic elements (Fig. 8).

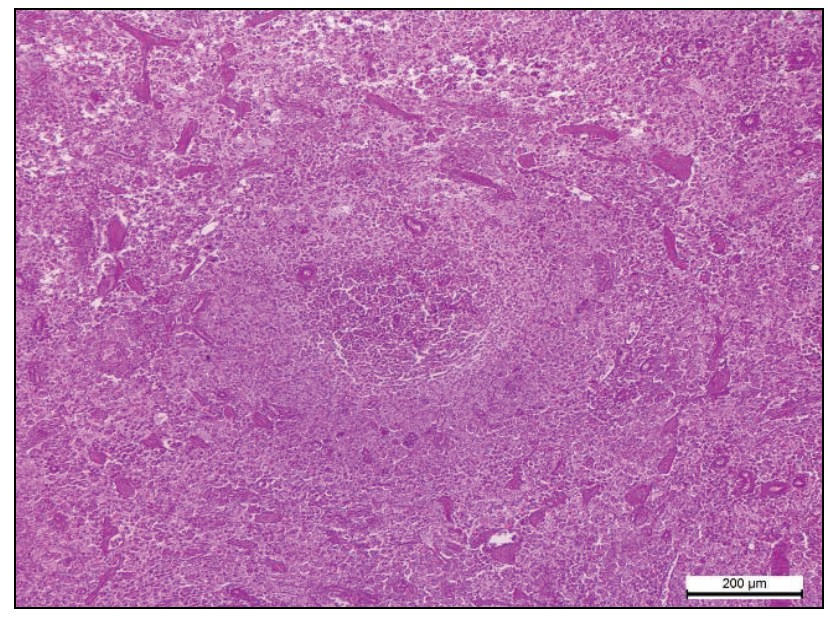

Fig. 7. Spleen of a cat with FIP: saturation of sinusoids and vessels of border zone of lymph node with PAS-positive protein mass; PAS-reaction

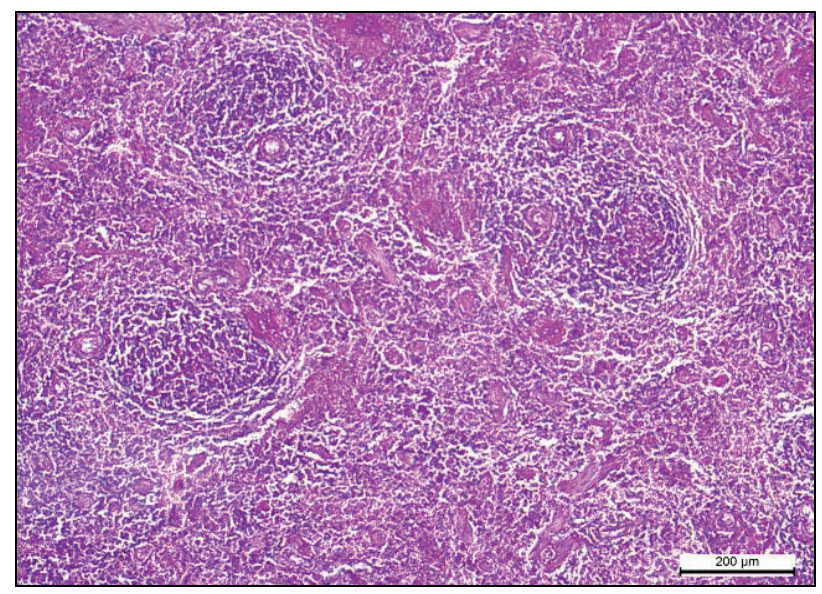

Fig. 8. Spleen of a cat with FIP: sedimentation of PAS-positive protein mass in the walls of arteries and reticular carcass of white pulp; PAS-reaction

On the preparations stained with haematoxylin and eosin, such elements in lymph nodes became of eosinphilic colour, which is caused by saturation of reticular structures and walls of vessels with proteins of blood plasma, including poorly dispersive protein - fibrinogen and leads to formation of untypical protein-polysugar complexes and was the basis for formation of fibrinoid (Fig. 9). During histochemical examination, this particular complex caused eosinphilic, PAS-positive reaction. Also, in five cases in reaction with Congo red, in the spleen of cats, we found accumulation of amyloid masses. Localization of amyloid masses was observed in the subendothelial layer of arterioles, along the reticular fibers of lymph nodes in the form of orange homogenous masses (Fig. 10). The spleens of two cats were enlarged, their edges became rounded, and 
the capsule tensioned. Bleeding of different extent was observed under the capsule (Fig. 11). Histological examination of the spleen of the abovementioned cats revealed a sharp decrease in hemodynamic, which was expressed in enlarging and oversaturation of the vessels with blood, stases and excessive saturation of red pulp with erythrocytes. Such marked plethora indicated increasing deposition of blood in the spleen (Fig. 12).

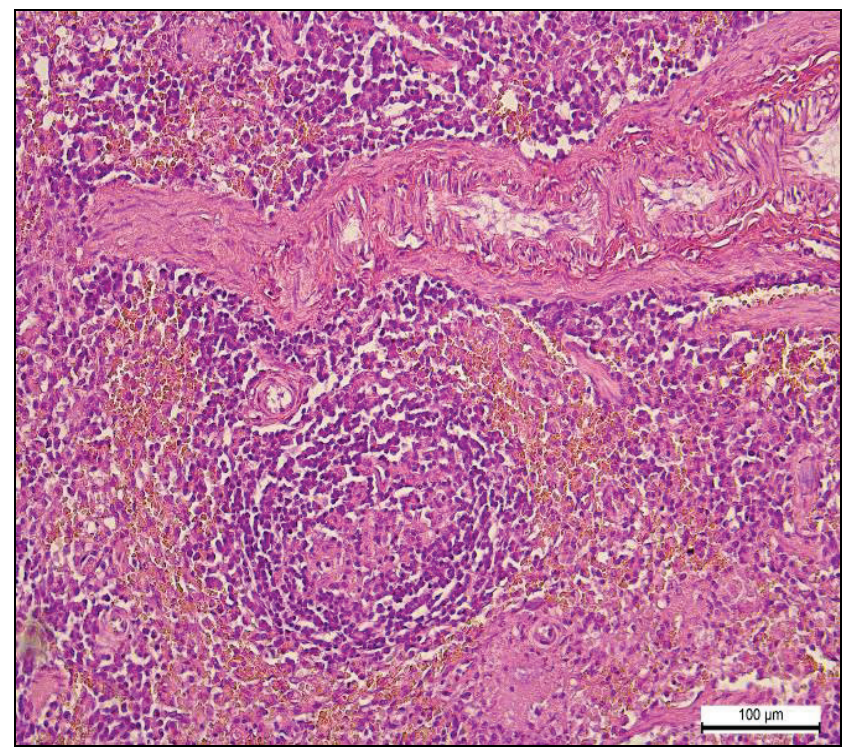

Fig. 9. Spleen of a cat with FIP: eosinophilic protein mass deposited along reticular fibers in the center of lymph node; haematoxilin and eosin

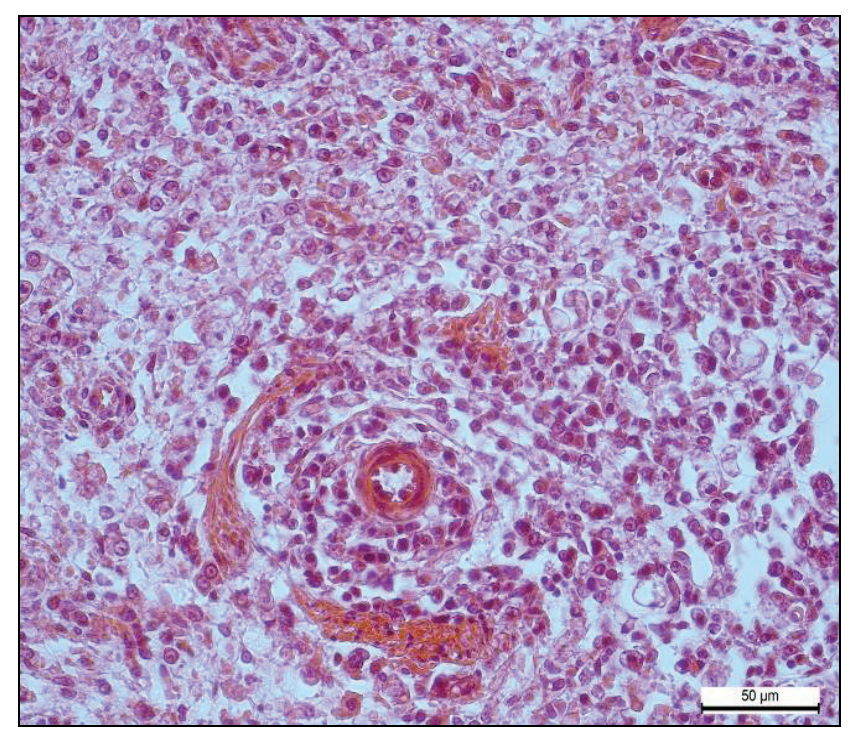

Fig. 10. Spleen of a cat with FIP: deposition of amyloid masses along the reticular fibers of lymph node and wall of blood vessel; Congo red

Disorders in capillary blood flow, increased transcapillary fluid exchange were caused by endotheliocytes. Destruction of endotheliocytes with disruption of the fibers in the wall of the vessels contributed to increase in their penetrability and was reflected in the phenomena of stromal, perivascular edemas of tissue and bleeding. Red pulp was filled with erythrocytes at different stages of decomposition. In the reticular structure of red pulp, we also observed thin cords formed by micro- and macrophages, but their number was much lower compared to the control animals. The number of megakaryocytes increased. Formation of megakaryocytes indicated increase in extramedullary haematopoiesis. As a result of plethora, the size of lymph nodes decreased. Perivascular edema and disruption of the fibers in the walls of vessels, steep accumulation of blood in red pulp contributed to increase in the organ's volume, which was observed during macroscopic examination. In one cat, the volume of the spleen increased, which was followed by fibrinous peri- splenitis. The surface was tuberous with layering, the capsule was wrinkled and covered with light-grey moderately fibrinous membranes, which at some places were hard to remove. Histological examination of the spleen revealed disruption of connective tissue fibers and saturation of capsules with fibrinous exudate. On the preparations stained using Van Gieson, among interlaced fibrin filaments, fiber structures of red colour were clearly distinguished, which indicated organisation of fibrin (Fig. 13).

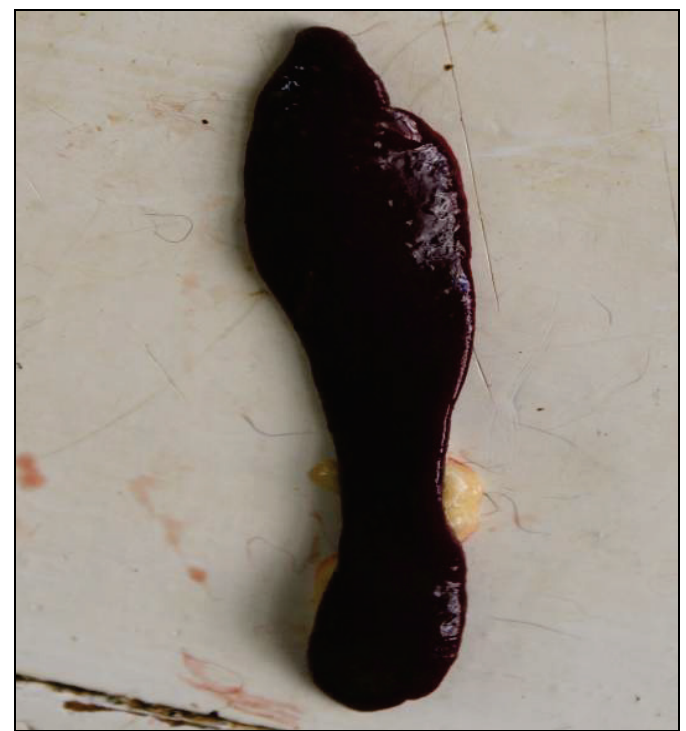

Fig. 11. Spleen of cat with FIP: tubular surface with overlapping

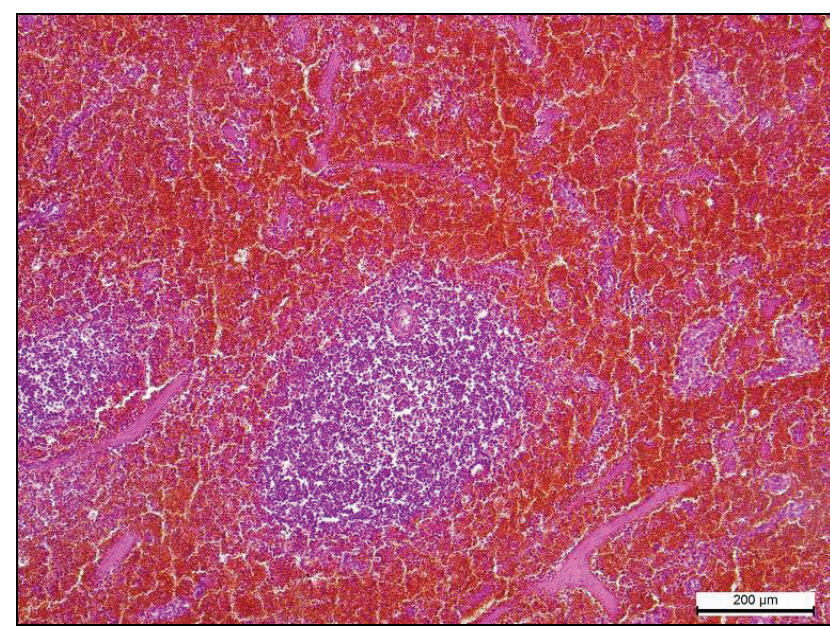

FIg. 12. Spleen of a cat with FIP: blood-filling of red pulp; depletion of lymph node; haematoxylin and eosin

In this organ, lymph nodes of white pulp were much larger compared to previous animals, but the mantle and marginal zones were unclear. In such lymph nodes, we clearly see the reticular carcass, where small groups of stretched lymphocytes were located in the periarterial zone (Fig. 14). The walls of the central arteries of lymph nodes were enlarged, the endothelium was at some places desquamated, which affected blood circulation. Centers of lymph nodes were stretched and deplated, observed to have karyorrhexis of cells of different intensity. The red pulp had moderate content of macrophages with grains of hemosiderin and cells of lysed nuclei.

Therefore, during the analysis of the results of pathomorphological examination of spleens of cats which suffered infectious peritonitis, we should mention that the structural changes were accompanied by steep depletion of lymph nodes by lymphocytes and decrease in the number of micro- and macrophages, which indicated reduction of white pulp, steep inhibition of activity of T- and B-lymphocytes, plasmacytic and macrophage reaction and manifested in development of immune-deficiency condition of the organism. Also, in the spleen, we observed mesenchymal disproteinosis, which was accompanied by fibrinoid 
swelling and amyloidosis of walls of vessels and deposition of fibrinoid and amyloid along the reticular fibers of lymph nodes.

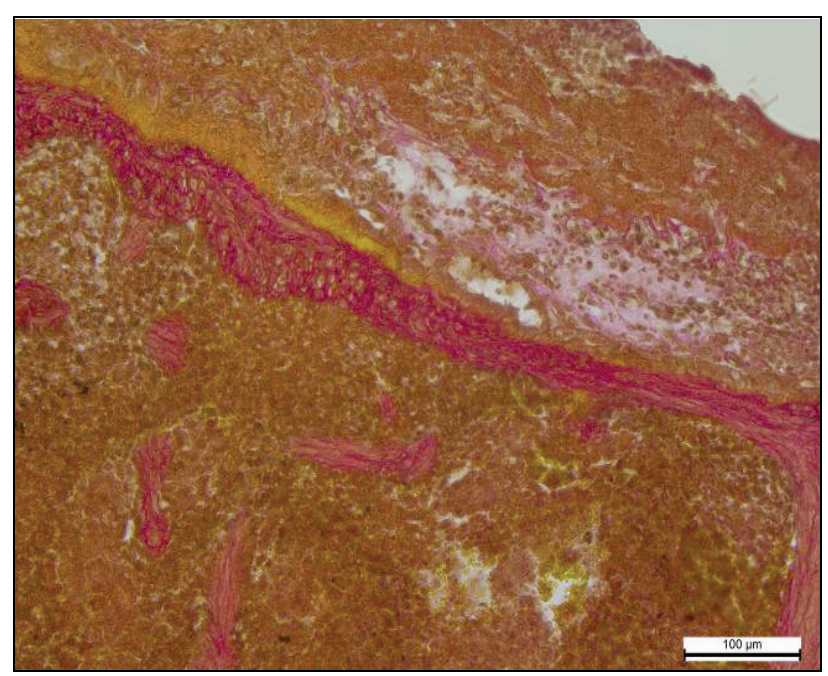

Fig. 13. Spleen of a cat with FIP: perisplenitis; organisation of fibrin; Van-Gieson

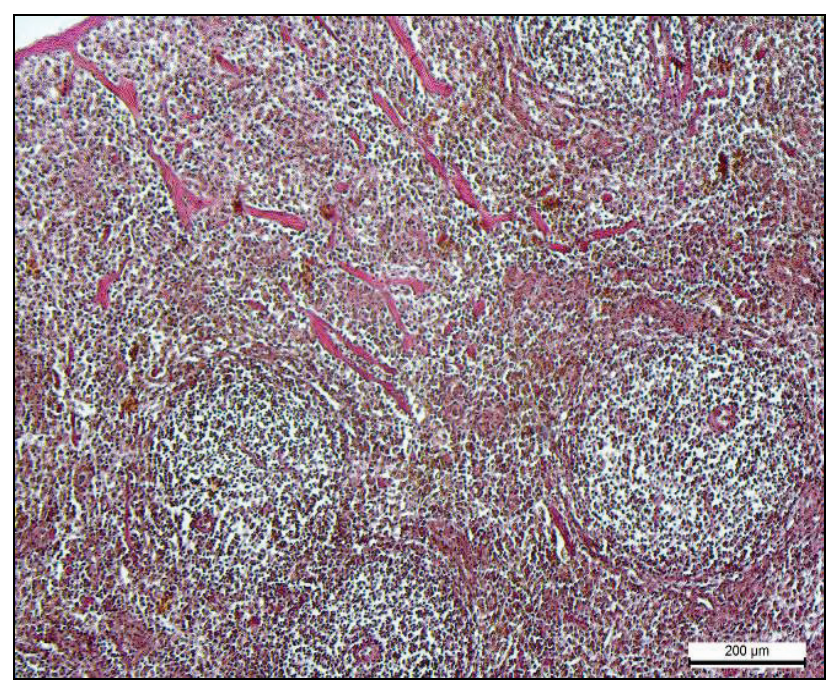

Fig. 14. Spleen of cat with FIP: periarterial zone of lymph nodes poorly filled with erythrocytes; Van-Gieson

Similar disorders in the system of T- and B-lymphocytes were observed also in mesenteric lymph nodes of cats suffering from FIP. During the histological examination, the capsula and stroma of lymph nodes were stretched, saturated with transudates rich in PAS-positive compounds (Fig. 15). Interstitial edema was followed by exposure of the reticular carcass of the adrenal and paracortical zone of lymph nodes and significant decrease in the subpopulation of blood elements in the organ. In the cortex, directly under the border sinuses, lymph nodes different in size but significantly decreased were clearly seen. At the same time, lymph nodes with reactive centers were not determined. At some places, between reticular fibers of paracortical zones, we could see single granulocytes, macrophages and small groups of apoptosis-changed lymphocytes. As we know, the paracortical zone is the T-dependant zone, through the postcapillary venules of which, migration of recirculating lymphocytes to parenchyma and lymph nodes occurs. We determined histostructural changes and severe inhibition of T-lymphocytes activity, and also weakening of cellular immunity (Fig. 15). On the preparations stained using iodine acid-Schiff, we determined significant fuchsinophility of not only the walls of vessels, sinusoids, reticular structures, and also detected PAS-positive filament structures in lumina of the vessels (Fig. 16).

Lower web-like alcianphilic structures were found in the vessels' lumina, sinuses, among aggregate erythrocytes on the preparations stained with alcian blue (Fig. 17). Presence of filament structures in lumina of the vessel system of lymph node indicates intravascular blood coagulation and blood circulation disorders during their life.

We observed dilatation of border and central sinuses and disorders in their structure. Walls of sinuses became exposed, at some places, there were seen singular endothelium cells. It seems that sinuses are formed by phagocytic cells, which are the first to contact the virus after the pathogens penetrate the organism, and then transform into macrophages. However, a small number of transformed cells became visible. Among turbid reticular cells, we found single macrophages. Quantitative composition of micro- and macrophages was sharply decreased. Lymph cords which branched from cortex and trabeculae were significantly narrowed and totally depleted, plasmatic cells were not found. Steep decrease in the number of T- and B-lymphocytes and plasma cells conditioned exposure of the reticular carcass of the paracortical and adrenal zones (Fig. 18). The determined changes in lymph nodes indicate development of clearly manifested atrophic processes of lymphoid tissue and immune-deficiency condition of the organism.

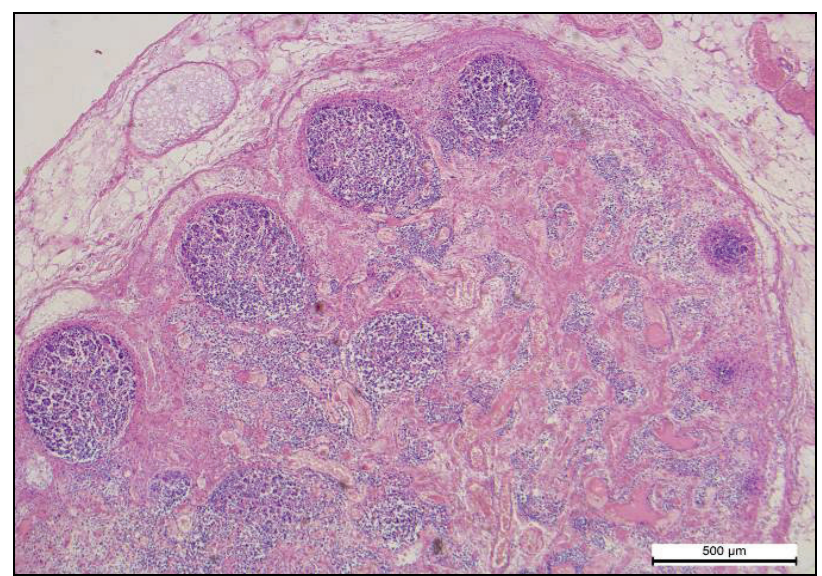

Fig. 15. Lymph node of a cat with FIP: different in size, but much smaller lymph nodes in the cortex zone

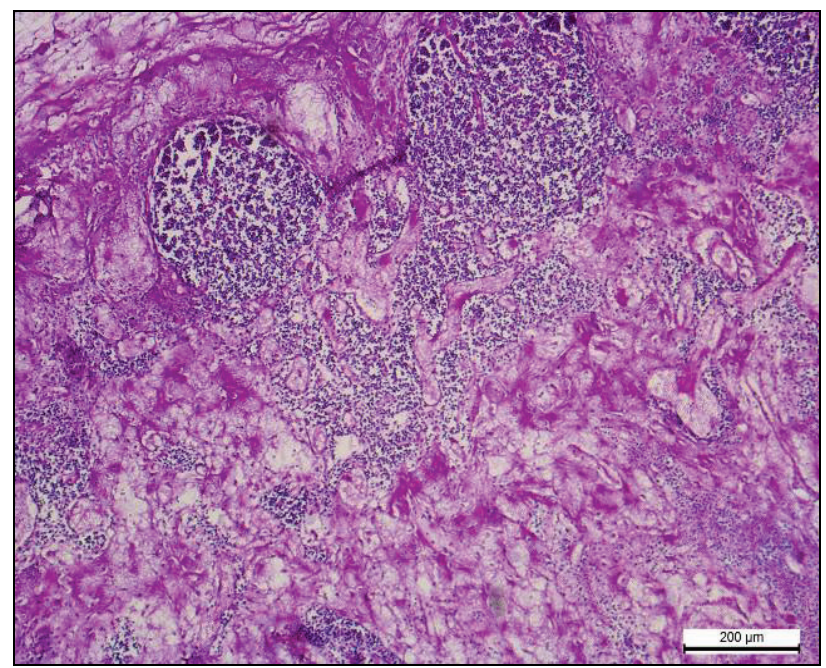

Fig. 16. Lymph node of a cat with FIP: the saturation of reticular carcass with PAS-positive masses; PAS-reaction

Analysis of the data obtained during histological examination of mesenteric lymph nodes of most of the cats which suffered feline infectious peritonitis demonstrated that edema and exposure of the reticular carcass of the adrenal and paracortical zones, dilatation of border and central sinuses were followed by a sharp decrease in the number of $\mathrm{T}$ - and B- lymphocytes, plasma cells, micro- and macrophages, which indicated development of atrophy processes of lymph tissue and immunedeficiency condition of the organism. Histostructural changes in lymphoid tissue were combined with thrombosis of the vessels. In the mesenteric lymph nodes of two cats that suffered from hemorrhagic hyperplasia of the spleen, atrophy of the lymph tissue was followed by 
significant enlargement of the blood vessels, plethora of the blood vessels, central sinuses, stases and bleeding in the organ's stroma (Fig. 19). The number of lymphocyte subpopulations both in the cortex, and in the adrenal zones steeply decreased. The lymph nodes were small and moderately filled with lymphocytes.

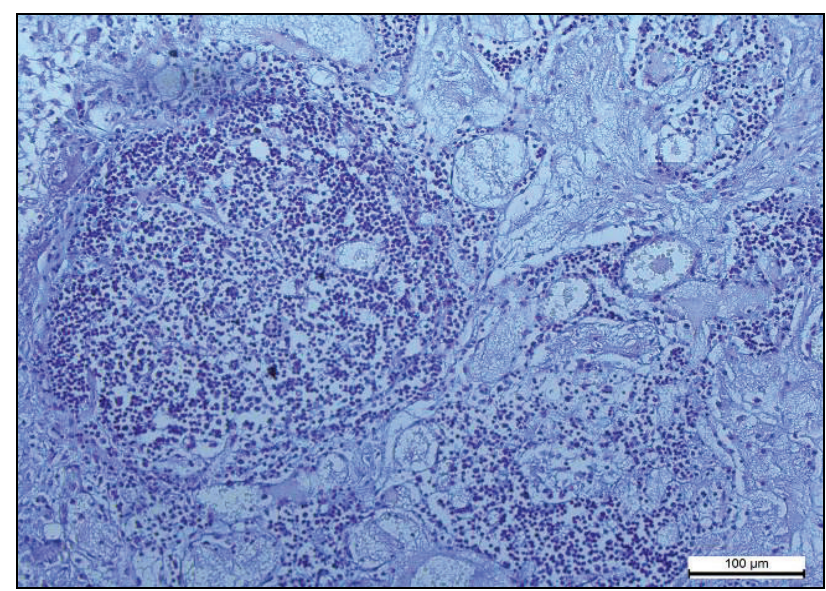

Fig. 17. Lymph node of a cat with FIP: exposure of reticular carcass of the paracortical zone; alcian blue

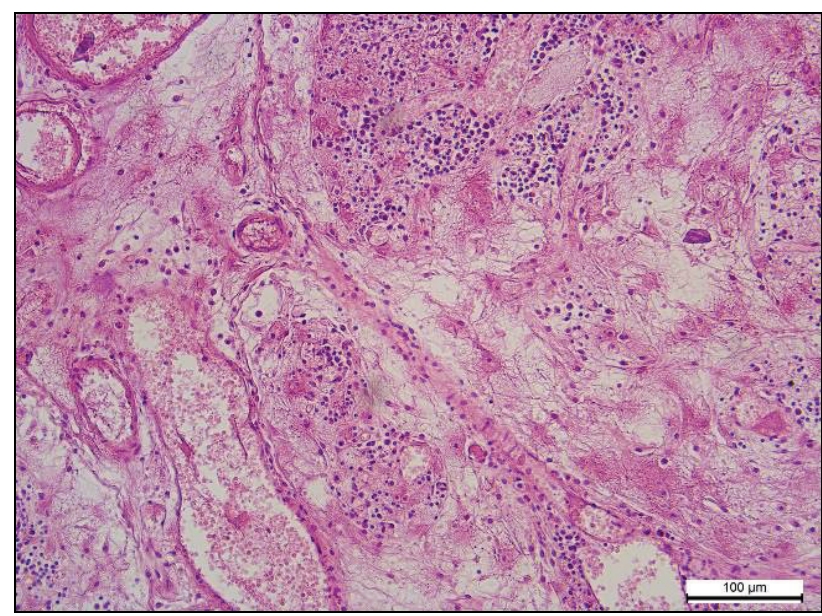

Fig. 18. Lymph node of a cat with FIP: depletion of lymph cords; haematoxilin and eosin

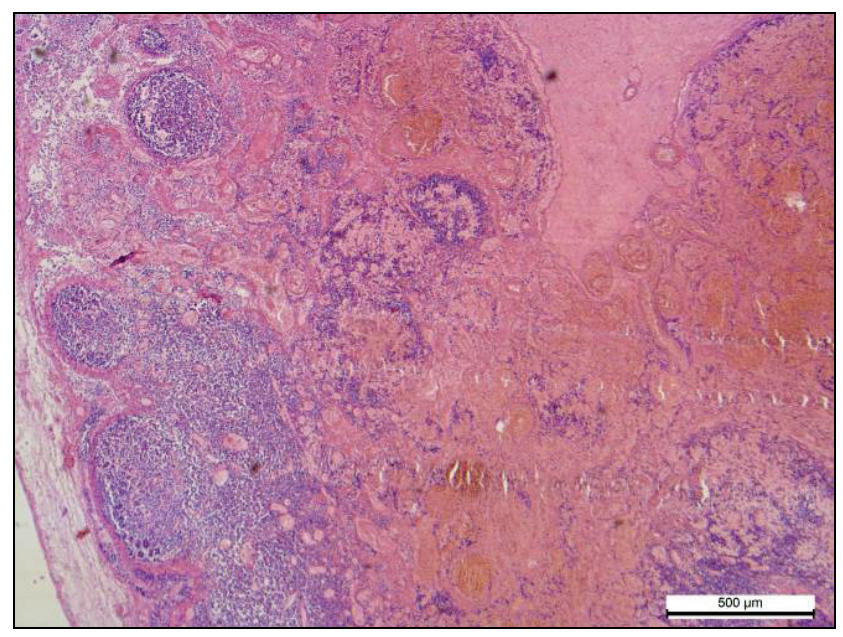

Fig. 19. Lymph node of a cat with FIP: enlargement and overfilling with blood of border and central sinuses, stasis and bleeding into stroma of the organ; haematoxilin and eosin

In three other cases, mesenteric lymph nodes of the cats were observed to show development of sinus histiocytosis. Cortex substance in lymph nodes was represented by poorly contoured, small lymph nodes.
There were small lymphatic nodes with widely distributed lymphocytes. As a result of decrease in the number of cellular elements in the central part of the lymph nodes, some lymph nodes were found to have bright centers (in the form of "starry sky"), which is considered to be a clear resistance reaction to pathogens. Density of lymphocytes in the cortex and paracortical zones was low. The saturation of cellular elements of RNA was also sharply decreased. Reticular tissue of the adrenal zone was also luminant, with enlarged sinuses (Fig. 20).

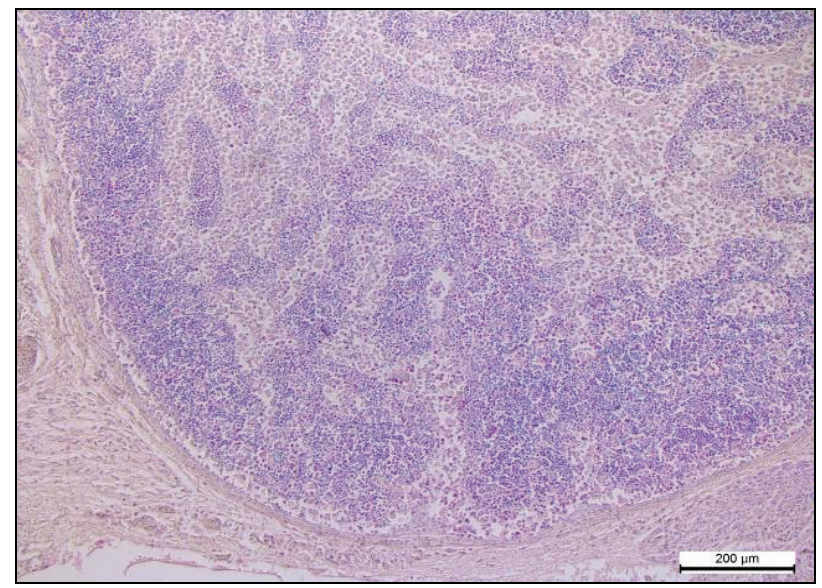

Fig. 20. Lymph node of a cat with FIP: narrowing of cortex; sharp decrease in lymph nodes; methyl green-pironin

Lymph cords were thinned, widely spread, and presented in the form of narrow tails filled with lymphoid elements. Compared to the previous animals, in the lymph cords, we found lymphocytes, lymphoblasts and a small number of plasmatic cells. The cytoplasm of the latter demonstrated moderate pirinophilic reaction during Brashe staining. There was a clear dilatation of the central sinuses, where the syncytial connection of endothelium cells was damaged. As we know, steep enlargement of sinuses is orientated towards strengthening of the processes of biological and mechanical filtration, phagocytosis and slowed flow of lymph through the enlarged sinuses. As a result of swelling and desquamation of sinusoidal endothelium cells, they were located in the lumina of sinuses in the form of rounded cells, among which single lymphocytes and macrophages were clearly distinguished. Many cells were in the state of necrobiosis (Fig. 21). Intense infiltration of sinuses by histiocytes at different stages of decomposition indicates development of sinusoidal histiocytosis.

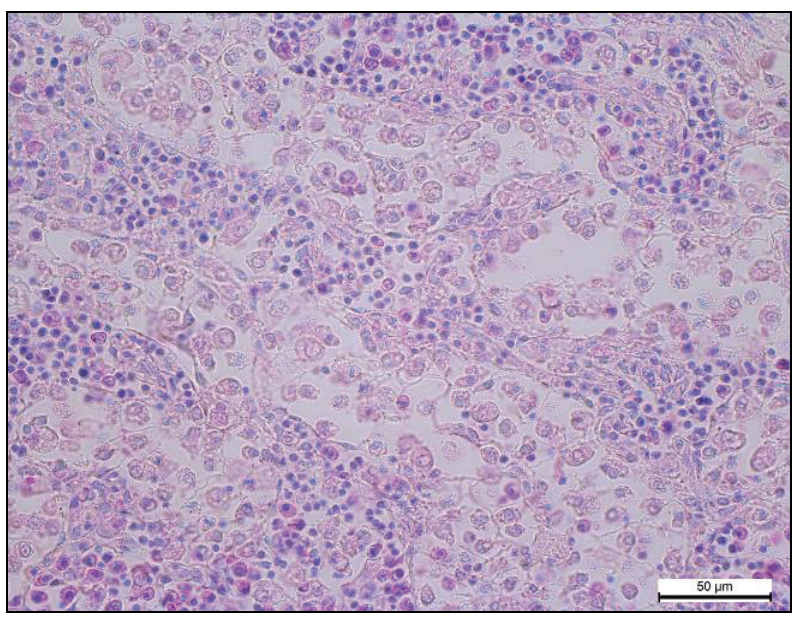

Fig. 21. Lymph node of a cat with FIP: lymph cords moderately filled with B-lymphocytes and single plasmatic cells; methyl green-pironin

During staining with iodine acid-Schiff, "shore" cells of the sinuses, which perform a filtration-phagocytic function, were seen on the preparations in the form of starry cells with mutually interlaced processes, often containing grainy fuchsinophilic elements. Clear fuchsinophilia was 
determined also for walls of arterioles and damaged structures of reticular fibers (Fig. 22).

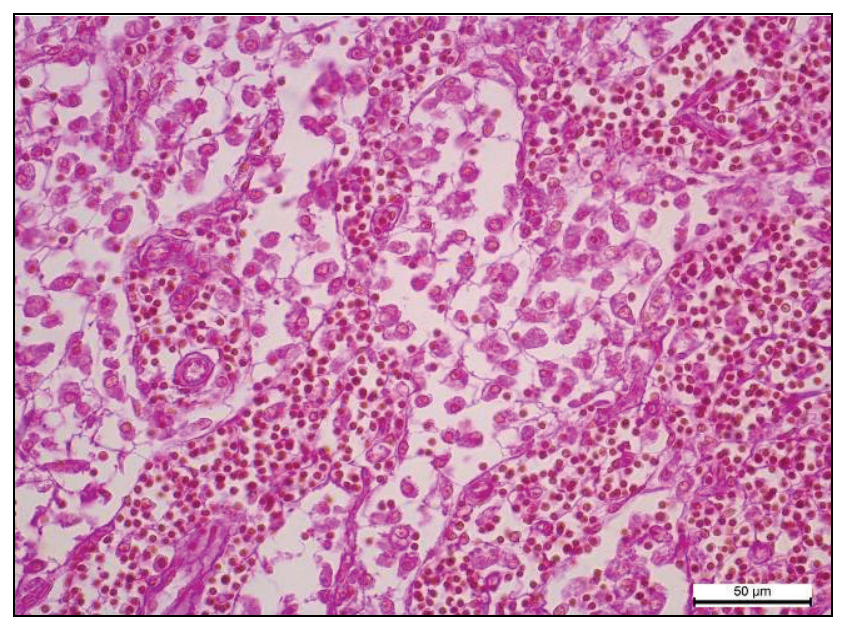

Fig. 22. Lymph node of a cat with FIP: lymph cords; fuchsinophilia of reticular fibers and walls of vessels; PAS-reaction

On the preparations stained with methyl green and pironin, we observed that sinus endothelial cells free of synthesis relations were present in the lumina of sinuses in the form of mostly rounded cells with poorly stained cytoplasm and nucleus, often with lysed nuclei. Small vacuoles were found in the cytoplasm and nuclei of most desquamated endothelial cells (Fig. 23). Also, we found cells with small pironinophilic elements in the cytoplasm (Fig. 24).

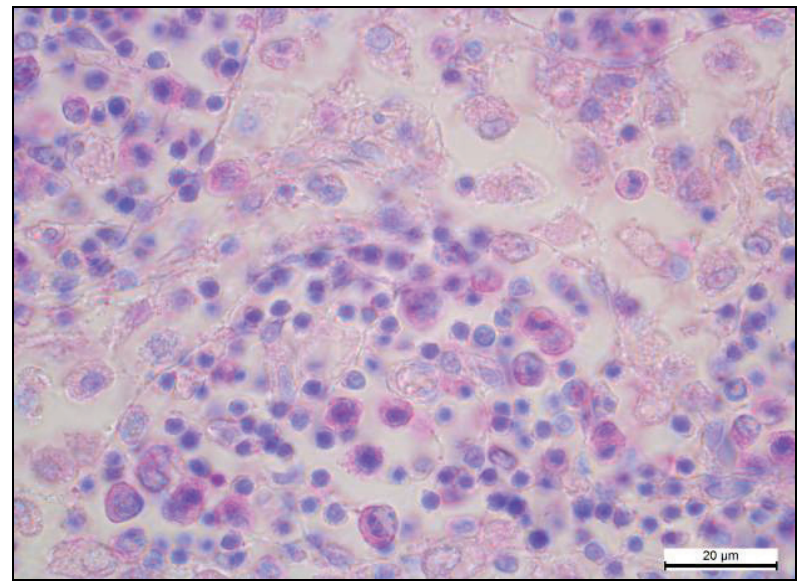

Fig. 23. Lymph node of a cat with FIP: lumen of sinuses of rounded cells, with poorly stained cytoplasm and nucleus; moderately filled with B-lymphocytes and single plasmatic cells; methyl green-pironin

Therefore, in the mesenteric lymph nodes of cats with FIP, edema and exposure of reticulary carcass and paracortical zone, dilatation of border and central sinuses were followed by steep decrease in the number of T- and B-lymphocytes, plasmatic cells, micro- and macrophages, which indicated development of atrophic processes in the lymphoid tissue and immune-suppressive condition of the organism. Histostructural changes in lymphoid tissue were combined with thrombosis of vessels. In two cases, the atrophy of lymphoid tissue was followed by dramatic enlargement and overfilling with blood of the blood vessels, central sinuses, stases and bleeding in the stroma of the organ, and three cats were recorded as having sinus histiocytosis.

\section{Discussion}

The peripheral organs of immunogenesis - spleen and lymph nodes are specific biological "filters" which disable antigens, and where antigen proliferation and differentiation of T- and B-lymphocytes takes place and where a particular immune response is formed. The main function of the spleen is its participation in many immunological processes, provision of development and activation of lymphocytes and their transformation into cells - primary producers of antibodies, or in cells which take part in the reaction of cellular immunity (Lucyk et al., 2003; Golovac'kyj et al., 2009; Kotsan et al., 2009; Vandevelde, 2015; Lucas, 2017; Golub et al., 2018).

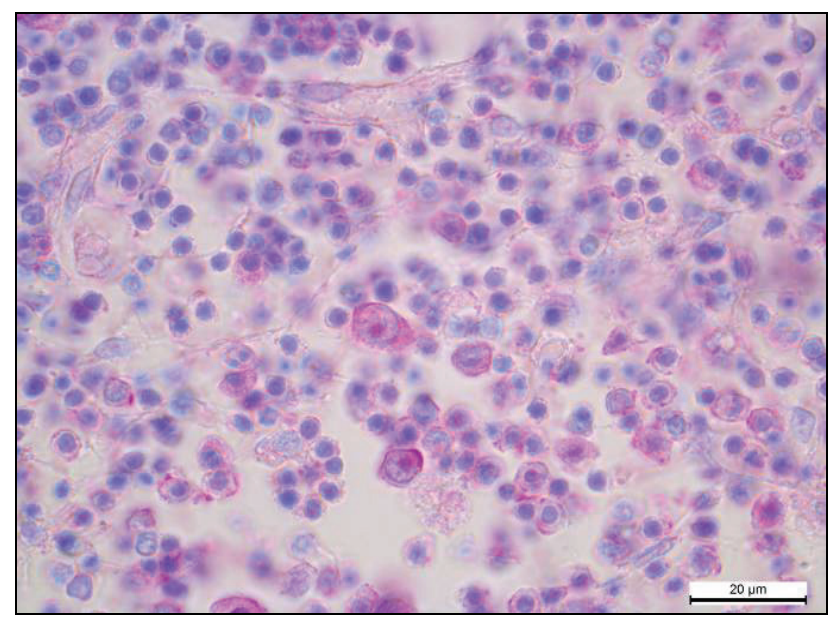

Fig. 24. Lymph node of a cat with FIP: cells with small pironinophilic elements in cytoplasm; methyl green-pironin

It has been determined that during infectious peritonitis, an excessive production of antibodies which are not controlled by suppressive lymphocytes occurs, leading to development of hypersensitivity of slowed type. Intensive production of defective neutralizing antibodies with formation of antigen-antibody complexes is distinctive for severe infectious peritonitis. Complexes in blood attach to macrophages and distribute them in the blood vessels. In the blood vessels, the antigen-antibody system is accompanied by the complement, and the complexes formed this way attach to the walls of vessels. These complexes are phagocytized by macrophages which stimulate accumulation of neutrophilic leukocytes through the factor of chemotaxis and lead to damage to endothelium and vessel wall, formation of thrombi (Hsieh et al., 2010; Brown, 2011; Kudrjashov \& Balabanova, 2011; Han et al., 2014; Günther et al., 2018; Jaimes \& Whittaker, 2018; Shirato et al., 2018).

In the case of structural changes in spleen, it should be mentioned that most of the studied animals were recorded having mesenchymal disproteinosis, which was followed by fibrinoid swelling, amyloidosis of walls of vessels and deposition of fibrinoid and amyloid along the reticular fibers of lymph nodes. I.e. in the spleen of the diseased cats, changes in the vessels of a non-inflammatory nature prevailed - angiopathy. One of the most important characteristics of development of pathological process in animals with infectious peritonitis is damage to the endothelium of vessels, which leads to heightened penetrability of the vessels, insudation of high molecular proteins and glycoproteins of blood, thus leading to disorders of protein-carbohydrate composition of the main substance (Rjemsi \& Tennant, 2005; Kudrjashov \& Balabanova, 2011). Formation of unusual protein-polysugar complexes became a basis for formation of fibrinoid which manifested significant eosinophilic PAS-positive reaction during histochemical examination. Also, during staining with Congo red, the spleens of the cats were observed to have deposition of amyloid masses in the intima of blood vessels and along the reticular fibers of lymph nodes.

Pathohistological changes in the spleen of the cats suffering from infectious peritonitis were characterized by steep depletion of lymph nodes by lymphocytes and decrease in the number of micro- and macrophages, which indicated reduction of white pulp, sharp inhibition of T- and B-lymphocytes' activity, which was possibly conditioned by long term persistence of the virus in the organism.

The morphological changes revealed in the mesenteric lymph nodes were mainly of one type, and slightly differed by extent of manifestation. We constantly found fuchsinophilic, alcianophilic filament structures in aggregated erythrocytes, which indicates the development 
of disseminated thrombosis, a peculiarity of which is development of interstitial edema, which took place in the peripheral organs of immunogenesis. Edema and exposure of reticular carcass of the adrenal and paracortical zones, dilatation of border and central sinuses were followed by steep decrease in the number of T- and B-lymphocytes, plasmatic cells, micro- and macrophages, which indicated development of atrophic processes in the lymph tissue.

Therefore, in infectious feline peritonitis, the peripheral organs of immunogenesis manifested development of mesenchymal disproteinosis, disseminated thrombosis, depletion of lymph nodes by lymphocytes, steep inhibition of activity of T- and B-lymphocytes, plasmocytic and macrophage reaction, which indicated the development of an immune-deficient condition of the organism.

\section{Conclusion}

Hematological parameters during the three week clinical progresssion of the course of the disease in cats demonstrated reduction of the hemoglobin concentration, number of erythrocytes and leukocytes. A possible decrease in the number of lymphocytes indicated development of an immune-deficiency condition. Also, during development of the disease, the animals had a possible increase in ESR, which indicates the development of inflammatory process in the organism and reduction in the number of thrombocytes, which conditioned the development of disseminated intravascular coagulation (DIC).

The spleen of the cats which suffered from infectious peritonitis underwent histostructural changes were accompanied by steep depletion of lymph nodes by lymphocytes and decrease in the number of micro- and macrophages, which indicated reduction of white pulp, steep inhibition of activity of T- and B-lymphocytes, plasmocytic and macrophage reaction and manifested in development of immune-deficiency condition of the organism. Also, mesenchymal disproteinosis was observed in the spleen,which was asccompanied by fibrinoid swelling and amyloidosis of walls of vessels and deposition of fibrinoid and amyloid along the reticular fibers of the lymph nodes.

In the mesenteric lymph nodes of most of the cats which suffered infectious peritonitis, the following symptoms were observed; edema and exposure of reticular carcasses of the adrenal and paracortical zones, dilatation of border and central sinuses, thrombosis of vessels, followed by steep decrease in the number of T- and B-lymphocytes, plasmatic cells, micro- and macrophages, which indicated the development of atrophic processes in lymphoid tissue and immune-suppression. In three cases, we recorded sinus histiocytosis in the mesenteric lymph nodes of cats.

\section{References}

Bálint, Á., Farsang, A., Szeredi, L., Zádori, Z., \& Belák, S. (2014). Recombinant feline coronaviruses as vaccine candidates confer protection in SPF but not in conventional cats. Veterinary Microbiology, 169(3-4), 154-162.

Baydar, E., Eröksüx, Y., \& Timurkan, M. O. (2014). Feline infectious peritonitis with distinct ocular involvement in a cat in Turkey. Kafkas Universitesi Veteriner Fakultesi Dergisi, 20(6), 961-965.

Brown, M. A. (2011). Genetic determinants of pathogenesis by feline infectious peritonitis virus. Veterinary Immunology and Immunopathology, 143(3-4), 265-268.

Crawford, A. H., Stoll, A. L., Sanchez-Masian, D., Shea, A., Michaels, J., Fraser, A. R., \& Beltran, E. (2017). Clinicopathologic features and magnetic resonance imaging findings in 24 cats with histopathologically confirmed neurologic feline infectious peritonitis. Journal of Veterinary Internal Medicine, 31(5), 1477-1486.

Gavrilin, P., Gavrilina, E., \& Evert, V. (2017). Histoarchitectonics of the parenchyma of lymph nodes of mammals with different structure of intranodal lymphatic channel. Ukrainian Journal of Ecology, 7(3), 96-107.

Golovac'kyj, A. S., Cherkasov, A. S., Sapin, M. R., \& Parahin, A. I. (2009). Anatomija ljudyny [Human anatomy]. Vol. 3. Nova Knyga, Vinnycja (in Ukrainian).

Golub, R., Tan, J., Watanabe, T., \& Brendolan, A. (2018). Origin and immunological functions of spleen stromal cells. Trends in Immunology, 39(6), 503-514.

Goral's'kyj, L. P., Homych, V. T., \& Konons'kyj, O. I. (2005). Osnovy gistologichnoi' tehniky i morfofunkcional'ni metody doslidzhen' u normi ta pry patologii' [Bases of histological technology and morphofunctional methods of research in norm and in pathology]. Polissja, Zhytomyr (in Ukrainian).
Günther, S., Felten, S., Wess, G., Hartmann, K., \& Weber, K. (2018). Detection of feline Coronavirus in effusions of cats with and without feline infectious peritonitis using loop-mediated isothermal amplification. Journal of Virological Methods, 256, 32-36.

Han, J.-I., Kang, S.-Y., Yoon, K.-J., \& Na, K.-J. (2014). Nucleic acid-based differential diagnostic assays for feline coronavirus. Journal of Virological Methods, 208, 21-25.

Hora, A. S., Tonietti, P. O., Taniwaki, S. A., Asano, K. M., Maiorka, P., Richtzenhain, L. J., \& Brandao, P. E. (2016). Feline Coronavirus 3c protein: A candidate for a virulence marker. BioMed Research International, 2016, e8560691.

Hsieh, L.-E., Lin, C.-N., Su, B.-L., Jan, T.-R., Chen, C.-M., Wang, C.-H., Lin, D.-S. Lin, C.-T., \& Chueh, L.-L. (2010). Synergistic antiviral effect of Galanthus nivalis agglutinin and nelfinavir against feline coronavirus. Antiviral Research, 88(1), 25-30.

Jaimes, J. A., \& Whittaker, G. R. (2018). Feline coronavirus: Insights into viral pathogenesis based on the spike protein structure and function. Virology, 517, 108-121.

Kim, Y., Liu, H., Kankanamalage, A. C. G., Weerasekara, S., Hua, D. H., Groutas, W. C., Chang, K.-O., \& Pedersen, N. C. (2016). Reversal of the Progression of fatal Coronavirus infection in cats by a broad-spectrum Coronavirus protease inhibitor. PLoS Pathogens, 12(3), e1005531.

Kipar, A., \& Meli, M. L. (2014). Feline infectious peritonitis: Still an enigma? Veterinary Pathology, 51(2), 505-526.

Knotek, Z., Toman, M., \& Faldyna, M. (2000). Clinical and immunological characteristics of cats affected by feline infectious peritonitis. Acta Veterinaria Bmo, 69(1), 51-60.

Kondrahin, I. P. (2004). Metody veterinarnoj klinicheskoj laboratornoj diagnostiki [Methods of veterinary clinical laboratory diagnostics]. Kolos, Moscow (in Russian).

Kotsan, I. Y., Hrynchuk, V. O., Velemets, V. K., Shvarts, L. O., Pykaliuk, V. S. \& Shevchuk, T. I. (2009). Anatomiia liudyny [Human anatomy]. Tsentr Uchbovoi Literatury, Kyiv (in Ukrainian).

Kudrjashov, A. A., \& Balabanova, V. I. (2011). Patologoanatomicheskaja diagnostika boleznej sobak i koshek [Pathological diagnosis of diseases of dogs and cats]. Institut Veterinarnoj Biologii, Saint Petersburg (in Russian).

Le Poder, S., Pham-Hung d'Alexandry d'Orangiani, A.-L., Duarte, L., Fournier, A., Horhogea, C., Pinhas, C., Vabret, A., \& Eloit, M. (2013). Infection of cats with atypical feline coronaviruses harbouring a truncated form of the canine type I non-structural ORF3 gene. Infection, Genetics and Evolution, 20, 488-494.

Lucas, S. B. (2017). Lymph node pathology in infectious diseases. Diagnostic Histopathology, 23(9), 420-430.

Lucyk, O. D., Ivanova, A. J., Kabak, K. S., \& Chajkovs'kyj, J. B. (2003). Gistologija ljudyny [Human histology]. Knyga Pljus, Kyiv (in Ukrainian).

Merkulov, G. A. (1969). Kurs patologogystolohycheskoj tekhnyky [The course of pathohistological technique]. Medycyna, Leningrad (in Russian).

Pedersen, N. C. (2014a). An update on feline infectious peritonitis: Virology and immunopathogenesis. The Veterinary Journal, 201(2), 123-132.

Pedersen, N. C. (2014b). An update on feline infectious peritonitis: Diagnostics and therapeutics. The Veterinary Journal, 201(2), 133-141.

Pedersen, N. C., Liu, H., Dodd, K. A., \& Pesavento, P. A. (2009). Significance of Coronavirus mutants in feces and diseased tissues of cats suffering from feline infectious peritonitis. Viruses, 1(2), 166-184.

Pedersen, N. C., Liu, H., Durden, M., \& Lyons, L. A. (2016). Natural resistance to experimental feline infectious peritonitis virus infection is decreased rather than increased by positive genetic selection. Veterinary Immunology and Immunopathology, 171, 17-20.

Pedersen, N. C., Liu, H., Gandolfi, B., \& Lyons, L. A. (2014). The influence of age and genetics on natural resistance to experimentally induced feline infectious peritonitis. Veterinary Immunology and Immunopathology, 162(1-2), 33-40.

Pyrs, J. (1962). Gistohimija [Histochemistry]. Izdatel'stvo Inostrannoj Literatury, Moscow (in Russian).

Rjemsi, J., \& Tennant, B. (2005). Infekcionnye bolezni sobak i koshek [Infectious diseases of dogs and cats]. Akvarium, Moscow (in Russian).

Shirato, K., Chang, H.-W., \& Rottier, P. J. M. (2018). Differential susceptibility of macrophages to serotype II feline coronaviruses correlates with differences in the viral spike protein. Virus Research, 255, 14-23.

Uillard, M., Tvedten, G., \& Tornval'd, G. (2004). Laboratornaja diagnostika v klinike melkih domashnih zhivotnyh [Small animal clinical diagnosis by laboratory methods]. Akvarium, Moscow (in Russian).

Vandevelde, K. (2015). Immunological barriers: Functional histology of the spleen. The Veterinary Journal, 205(1), 3-4.

Ziółkowska, N., Paździor-Czapula, K., Lewczuk, B., Mikulska-Skupień, E., Przybylska-Gornowicz, B., Kwiecińska, K., \& Ziółkowski, H. (2017). Feline infectious peritonitis: Immunohistochemical features of ocular inflammation and the distribution of viral antigens in structures of the eye. Veterinary Pathology, 54(6), 933-944. 